\title{
The additional facet of immunoscore: immunoprofiling as a possible predictive tool for cancer treatment
}

\author{
Paolo A Ascierto ${ }^{1 *}$, Mariaelena Capone ${ }^{1}$, Walter J Urba ${ }^{2}$, Carlo B Bifulco ${ }^{2}$, Gerardo Botti ${ }^{1}$, Alessandro Lugli ${ }^{3}$, \\ Francesco M Marincola ${ }^{4}$, Gennaro Ciliberto', Jérôme Galon ${ }^{5,6,7}$ and Bernard A Fox ${ }^{2,8}$
}

\begin{abstract}
Recent investigations of the tumor microenvironment have shown that many tumors are infiltrated by inflammatory and lymphocytic cells. Increasing evidence suggests that the number, type and location of these tumor-infiltrating lymphocytes in primary tumors has prognostic value, and this has led to the development of an 'immunoscore. As well as providing useful prognostic information, the immunoscore concept also has the potential to help predict response to treatment, thereby improving decision- making with regard to choice of therapy. This predictive aspect of the tumor microenvironment forms the basis for the concept of immunoprofiling, which can be described as 'using an individual's immune system signature (or profile) to predict that patient's response to therapy' The immunoprofile of an individual can be genetically determined or tumor-induced (and therefore dynamic). Ipilimumab is the first in a series of immunomodulating antibodies and has been shown to be associated with improved overall survival in patients with advanced melanoma. Other immunotherapies in development include anti-programmed death 1 protein (nivolumab), anti-PD-ligand 1, anti-CD137 (urelumab), and anti-OX40. Biomarkers that can be used as predictive factors for these treatments have not yet been clinically validated. However, there is already evidence that the tumor microenvironment can have a predictive role, with clinical activity of ipilimumab related to high baseline expression of the immune-related genes FoxP3 and indoleamine 2,3dioxygenase and an increase in tumor-infiltrating lymphocytes. These biomarkers could represent the first potential proposal for an immunoprofiling panel in patients for whom anti-CTLA-4 therapy is being considered, although prospective data are required. In conclusion, the evaluation of systemic and local immunological biomarkers could offer useful prognostic information and facilitate clinical decision making. The challenge will be to identify the individual immunoprofile of each patient and the consequent choice of optimal therapy or combination of therapies to be used.
\end{abstract}

Keywords: Tumor microenvironment, Tumor-infiltrating lymphocytes, Immunoprofiling, Immunotherapy, Ipilimumab

Recent investigations of the tumour microenvironment (TME) have shown that many tumors are heavily infiltrated by a complex repertoire of inflammatory and lymphoid cells. Immune cells appear as dense infiltrates in the center of the tumoral zone, at the invasive margin of the tumor, and as lymphoid islets adjacent to the tumor. Increasing evidence supports the hypothesis that

\footnotetext{
* Correspondence: paolo.ascierto@gmail.com

'Melanoma, Cancer Immunotherapy and Innovative Therapy Unit, Istituto

Nazionale Tumori Fondazione "G. Pascale", Napoli, Italy

Full list of author information is available at the end of the article
}

the number, type and location of tumor-infiltrating lymphocytes (TILs) in primary tumors have prognostic value, and this has led to the development of the new concept of "immunoscore", e.g. a quantifiable measure of the infiltrate that can potentially be used as a prognostic factor [1]. This immunoscore is primarily based on the density of two lymphocyte populations, cytotoxic (CD8) and memory (CD45RO) T cells (CD3/CD45RO, $\mathrm{CD} 3 / \mathrm{CD} 8$ or $\mathrm{CD} 8 / \mathrm{CD} 45 \mathrm{RO}$ ), both in the center and the invasive margins of tumors [2-4].

\section{Biomed Central}

(c) 2013 Ascierto et al.; licensee BioMed Central Ltd. This is an Open Access article distributed under the terms of the Creative Commons Attribution License (http://creativecommons.org/licenses/by/2.0), which permits unrestricted use, distribution, and reproduction in any medium, provided the original work is properly cited. 
Although colorectal cancer has been the model for proof of principle during research development of the immunoscore, the relevance of the CD8 $+(C D 45 R O$ or CD3) phenotype has also been shown in other tumor types, with high densities of cytotoxic and memory $\mathrm{T}$ cells associated with longer disease-free (after surgical resection of the primary tumor) and/or overall survival in several cancer types [5]. However, the nature of TILs is heterogeneous between tumors and so, in order to further validate the concept of the immunoscore as a prognostic factor, this needs to be characterized in other tumor types such as melanoma, renal cell, prostate, ovarian and breast cancer. Studies have already begun to investigate the relationship between Immunoscore-like markers and prognosis in cancers other than colorectal. For example, a retrospective study involving 102 women with a histologically confirmed diagnosis of early invasive breast cancer recently reported that an increased CD68 count and CD68/(CD3 + CD20) ratio at the invasive front of the carcinoma was significantly associated with occurrence of distant metastasis [6]. Further, the reverse phenotype (CD68 $\left.8^{\text {low }} / \mathrm{CD} 4^{\text {low }} / \mathrm{CD} 8^{\text {high }}\right)$ was identified as an independent prognostic indicator of breast cancer survival $(\mathrm{p}<0.001)$ in a retrospective study of 677 patients [7].

As well as providing useful prognostic information, the immunoscore concept also has the potential to help predict response to treatment, thereby helping improve therapeutic decisions. This predictive aspect of the quantity, quality, and distribution of the immunologic TME forms the basis for the concept of immunoprofiling, which can be defined as "using an individual's immune system signature to predict the response to therapy" (see Table 1). The immunoprofile of an individual can be genetically determined or tumor-induced (and therefore dynamic). For example, it has previously been reported that some regional lymph nodes close to primary melanomas and breast cancers are immune-suppressed and that the degree of immune suppression is directly correlated with the closeness of the node to the tumor [8]. It has also been demonstrated that interdigitating dendritic cells are reduced and lack the complex dendrites that characterize active antigen presentation in nodes proximal to the tumor or partly replaced by tumor (e.g. sentinel lymph nodes). This could suggest nodal immune suppression due to tumor influence, mediated in part by melanomaderived materials [9].

With the advent of immunotherapies, the predictive role of immunoprofiling will become a fundamental tool for patients' management. Ipilimumab, a monoclonal antibody which antagonizes cytotoxic $\mathrm{T}$ lymphocyteassociated antigen 4 (CTLA-4), is the first in a series of immunomodulating antibodies to become available. Tumors typically develop multiple mechanisms to evade the endogenous immune response, including immune checkpoints' that can terminate immune responses after antigen activation. Immune checkpoint inhibitors, such as ipilimumab, have thus been a key target in the development of immunotherapeutic approaches for cancer. Treatment with ipilimumab has been shown to be associated with improved overall survival in patients with advanced melanoma [10]. Other immunotherapies currently being evaluated in clinical trials include anti-programmed death 1 (PD1) protein (nivolumab), anti-PD-ligand 1 (PDL1) and anti-CD137 (urelumab), and anti-OX40 [10-13].

Biomarkers that can be used as predictive factors for ipilimumab treatment have not yet been identified. However, there is already evidence that characteristic TMEs can have a predictive role. A retrospective study in patients treated with ipilimumab suggested that clinical activity was related to high expression of the immune-

Table 1 Differences between immunoscore and immunoprofiling

\begin{tabular}{lcc}
\hline Number of immune markers & $\begin{array}{c}\text { Immunoscore } \\
\text { Prognostic/Predictive(?) }\end{array}$ & $\begin{array}{c}\text { Immunoprofiling } \\
\text { Prognostic/Predictive(?) }\end{array}$ \\
\hline Immunoscore markers & $2-4$ & $1-$ Several \\
\hline Immunoscore-like markers & CD3/CD8 & Immune gene signatures \\
Multiplex assays \\
CD3/CD8/CD20/FoxP3 \\
CD3/CD8/CD45RO \\
CD4/CD8/CD68
\end{tabular}


related genes FoxP3 and indoleamine 2,3-dioxygenase (IDO) at baseline and an increase from baseline in TILs (at week 4) in tumor biopsies [14]. These biomarkers could represent the first potential proposal for an immunoprofiling panel in patients for whom anti-CTLA-4 therapy is being considered. However, these findings need to be confirmed in a large, prospective clinical trial. Similarly, in a recent study of the new anti-PD-1 agent nivolumab, preliminary findings suggested that the immunosuppressive PD-1 ligand, PD-L1 (B7-H1), could be a possible predictive biomarker of therapeutic response. In a subset of patients $(n=42)$ with various cancers, $36 \%$ with positive PD-L1 expression on the surface of tumor cells in pre-treatment tumor specimens had an objective response to treatment with anti-PD-1, while none of the patients with PD-L1-negative tumors had an objective response [15]. Again, prospective studies are needed to define the potential role of this biomarker. Other cells such as myeloid derived suppressor cells (MDSC) can be detected as infiltrating components of primary or metastatic lesions, suggesting a potential involvement in melanoma progression. Moreover, this kind of cells could have a role in predicting the response to ipilimumab [16].

This approach could form the basis for the evaluation of other immunomodulating antibody targets as possible predictive markers. Anti-PD-L1, anti-Lag3, anti-KIR, anti-TIM-3, anti-GITR, anti-OX40 and anti-CD137 represent the future of immunotherapy and it may be that assessment of the relevant markers can help define the individual immune system profile. This can then be used to help guide treatment choices with the different immunotherapies, used either alone or in combination.

Effective Immunoprofiling will not only consider the surface receptors of immune system cells, but also the presence of ectopic immune structures such as the tumorlocalized ectopic lymph node-like structures (TL-ELNs) [17]. Recently, it was demonstrated that a 12-chemokine gene expression signature (CCL2, CCL3, CCL4, CCL5, CCL8, CCL18, CCL19, CCL21, CXCL9, CXCL10, CXCL11, and CXCL13) is strongly associated with the presence of TL-ELNs, and with a better patient outcome in colorectal cancer and melanoma [18].

In conclusion, increasing evidence supports the view that cancer development is strongly influenced by the host immune system. The evaluation of systemic and local immunological biomarkers could offer useful prognostic information and facilitate clinical decision making about the need for specific therapies, and the 'immunoscore' concept is quickly gaining momentum with additional trials, research activity, and retrospective validations. More patient-specific immunoprofiling represents yet another step toward personalized medicine, incorporating tests that inform clinicians and patients toward clear decision-making.

\section{Competing interest}

PAA is consultant for Merck Sharp \& Dohme and Bristol-Myers Squibb. He has participated in advisory boards for Bristol-Myers Squibb, Merck Sharp \& Dohme, Roche-Genentech, GlaxoSmithKline, Amgen, Celgene, Medimmune, and Novartis and has received honoraria from Bristol-Myers Squibb, Merck Sharp \& Dohme, and Roche-Genentech. He has received research support for immunoscore projects from Bristol-Myers Squibb and Ventana-Roche. WU has received honoraria from Bristol-Myers Squibb. JG is a consultant for Roche. BAF has received research support for immunoscore projects from Bristol-Myers Squibb and Ventana-Roche. All other authors have no competing interest.

\section{Authors' contributions}

All Authors drafted and approved the final manuscript.

\section{Author details}

${ }^{1}$ Melanoma, Cancer Immunotherapy and Innovative Therapy Unit, Istituto Nazionale Tumori Fondazione "G. Pascale", Napoli, Italy. ${ }^{2}$ Earle A. Chiles Research Institute, Robert W. Franz Cancer Research Center, Providence Portland Medical Center, 4805 NE Glisan, St. Portland, OR, USA. ${ }^{3}$ Clinical Pathology Division and Translational Research Unit (TRU), Institute of Pathology, University of Bern, Bern, Switzerland. ${ }^{4}$ Sidra Medical and Research Centre, Doha, Qatar. ${ }^{5}$ INSERM, U872, Laboratory of Integrative Cancer Immunology, Paris F-75006, France. 'Université Paris Descartes, Paris, France. ${ }^{7}$ Cordeliers Research Centre, Université Pierre et Marie Curie, Paris 6, Paris, France. ${ }^{8}$ Department of Molecular Microbiology and Immunology, and Knight Cancer Institute, Oregon Health and Science University, Portland, OR 97239, USA.

Received: 28 February 2013 Accepted: 28 February 2013

Published: 3 March 2013

\section{References}

1. Galon J, Pagès F, Marincola FM, Thurin M, Trinchieri G, Fox BA, Gajewski TF, Ascierto PA: The immune score as a new possible approach for the classification of cancer. J Trans/ Med 2012, 10:1.

2. Galon J, Costes A, Sanchez-Cabo F, Kirilovsky A, Mlecnik B, Lagorce-Pagès C, Tosolini M, Camus M, Berger A, Wind P, Zinzindohoué F, Bruneval P, Cugnenc PH, Trajanoski Z, Fridman WH, Pagès F: Type, density, and location of immune cells within human colorectal tumors predict clinical outcome. Science 2006, 313:1960-1964.

3. Mlecnik B, Tosolini M, Kirilovsky A, Berger A, Bindea G, Meatchi T, Bruneval P, Trajanoski Z, Fridman WH, Pagès F, Galon J: Histopathologic-based prognostic factors of colorectal cancers are associated with the state of the local immune reaction. J Clin Oncol 2011, 29:610-618.

4. Pagès F, Kirilovsky A, Mlecnik B, Asslaber M, Tosolini M, Bindea G, Lagorce $C$, Wind P, Marliot F, Bruneval P, Zatloukal K, Trajanoski Z, Berger A, Fridman WH, Galon J: In situ cytotoxic and memory T cells predict outcome in patients with early-stage colorectal cancer. J Clin Oncol 2009, 27:5944-5951.

5. Fridman WH, Pages F, Sautes-Fridman C, Galon J: The immune contexture in human tumours: impact on clinical outcome. Nat Rev Cancer 2012, 12:298-306.

6. Eiró N, Pidal I, Fernandez-Garcia B, Junquera S, Lamelas ML, Del Casar JM, González LO, López-Muñiz A, Vizoso FJ: Impact of CD68/(CD3 + CD20) ratio at the invasive front of primary tumors on distant metastasis development in breast cancer. PLoS One 2012, 7:e52796.

7. DeNardo DG, Brennan DJ, Rexhepaj E, Ruffell B, Shiao SL, Madden SF, Gallagher WM, Wadhwani N, Keil SD, Junaid SA, Rugo HS, Hwang ES, Jirström K, West BL, Coussens LM: Leukocyte complexity predicts breast cancer survival and functionally regulates response to chemotherapy. Cancer Discov 2011, 1:54-67.

8. Cochran AJ, Wen D-R, Farzad Z, Stene MA, McBride W, Lana AM, Hoon DS, Morton DL: Immune suppression by melanoma cells as a factor in the generation of metastatic disease. Anticancer Res 1989, 9:859-864.

9. Cochran AJ, Morton DL, Stern S, Lana AM, Essner R, Wen DR: Sentinel lymph nodes show profound Downregulation of antigen-presenting cells of the Paracortex: implications for tumor biology and treatment. Mod Pathol 2001, 14:604-608.

10. Hodi FS, O'Day SJ, McDermott DF, Weber RW, Sosman JA, Haanen JB, Gonzalez R, Robert C, Schadendorf D, Hassel JC, Akerley W, van den 
Eertwegh AJ, Lutzky J, Lorigan P, Vaubel JM, Linette GP, Hogg D, Ottensmeier CH, Lebbé C, Peschel C, Quirt I, Clark Jl, Wolchok JD, Weber JS, Tian J, Yellin MJ, Nichol GM, Hoos A, Urba WJ: Improved survival with ipilimumab in patients with metastatic melanoma. N Engl J Med 2010, 363:711-723.

11. Ascierto PA, Simeone E, Sznol M, Fu YX, Melero I: Clinical experiences with anti-CD137 and anti-PD1 therapeutic antibodies. Semin Oncol 2010, 37:508-516.

12. Kline J, Gajewski TF: Clinical development of $m A$ bs to block the PD1 pathway as an immunotherapy for cancer. Curr Opin Investig Drugs 2011, 11:1354-1359.

13. Weinberg AD, Morris NP, Kovacsovics-Bankowski M, Urba WJ, Curti BD: Science gone translational: the OX40 agonist story. Immunol Rev 2011 244:218-231.

14. Hamid O, Schmidt H, Nissan A, Ridolfi L, Aamdal S, Hansson J, Guida M, Hyams DM, Gómez H, Bastholt L, Chasalow SD, Berman D: A prospective phase II trial exploring the association between tumor microenvironment biomarkers and clinical activity of ipilimumab in advanced melanoma. J Trans/ Med 2011, 9:204.

15. Topalian SL, Hodi FS, Brahmer JR, Gettinger SN, Smith DC, McDermott DF, Powderly JD, Carvajal RD, Sosman JA, Atkins MB, Leming PD, Spigel DR, Antonia SJ, Horn L, Drake CG, Pardoll DM, Chen L, Sharfman WH, Anders RA, Taube JM, McMiller TL, Xu H, Korman AJ, Jure-Kunkel M, Agrawal S, McDonald D, Kollia GD, Gupta A, Wigginton JM, Sznol M: Safety, activity, and immune correlates of anti-PD-1 antibody in cancer. N Engl J Med 2012, 366:2443-2454.

16. Ascierto PA, Kalos M, Schaer DA, Callahan MK, Wolchok JD: Biomarkers for immunostimulatory monoclonal antibodies in combination strategies for melanoma and other tumor types. Clin Cancer Res 2013. in press).

17. Coppola D, Nebozhyn M, Khalil F, Dai H, Yeatman T, Loboda A, Mulé JJ: Unique ectopic lymph node-like structures present in human primary colorectal carcinoma are identified by immune gene array profiling. Am J Pathol 2011, 179:37-45.

18. Messina JL, Fenstermacher DA, Eschrich S, Qu X, Berglund AE, Lloyd MC, Schell MJ, Sondak VK, Weber JS, Mulé JJ: 12-Chemokine gene signature identifies lymph node-like structures in melanoma: potential for patient selection for immunotherapy? Sci Rep 2012, 2:765.

doi:10.1186/1479-5876-11-54

Cite this article as: Ascierto et al:: The additional facet of immunoscore: immunoprofiling as a possible predictive tool for cancer treatment.

Journal of Translational Medicine 2013 11:54.

\section{Submit your next manuscript to BioMed Central and take full advantage of:}

- Convenient online submission

- Thorough peer review

- No space constraints or color figure charges

- Immediate publication on acceptance

- Inclusion in PubMed, CAS, Scopus and Google Scholar

- Research which is freely available for redistribution 